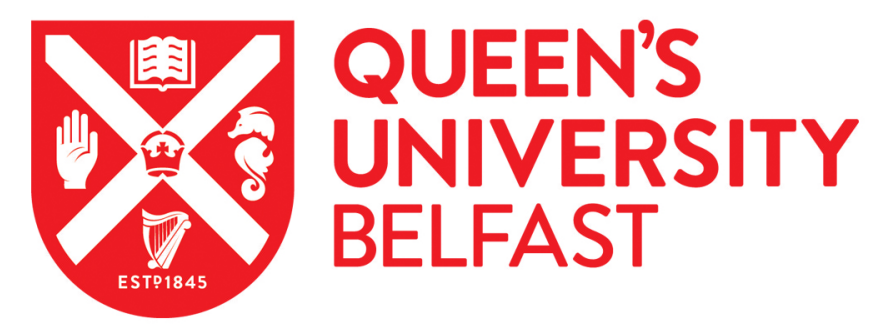

\title{
Perceived control and quality of life among recipients of implantable cardioverter defibrillator
}

Hammash, M., McEvedy, S., Wright, J., Cameron, J., Miller, J., Ski, C., Thompson, D. R., M, B., Wimsatt, A., Schrader, M., Smith, RV., Chung, M., \& Moser, D. (2019). Perceived control and quality of life among recipients of implantable cardioverter defibrillator. Australian Critical Care, 32(5), 383-390.

https://doi.org/10.1016/j.aucc.2018.08.005

Published in:

Australian Critical Care

Document Version:

Peer reviewed version

Queen's University Belfast - Research Portal:

Link to publication record in Queen's University Belfast Research Portal

\section{Publisher rights}

Copyright 2018 Elsevier

This manuscript is distributed under a Creative Commons Attribution-NonCommercial-NoDerivs License

(https://creativecommons.org/licenses/by-nc-nd/4.0/), which permits distribution and reproduction for non-commercial purposes, provided the author and source are cited.

\section{General rights}

Copyright for the publications made accessible via the Queen's University Belfast Research Portal is retained by the author(s) and / or other copyright owners and it is a condition of accessing these publications that users recognise and abide by the legal requirements associated with these rights.

Take down policy

The Research Portal is Queen's institutional repository that provides access to Queen's research output. Every effort has been made to ensure that content in the Research Portal does not infringe any person's rights, or applicable UK laws. If you discover content in the Research Portal that you believe breaches copyright or violates any law, please contact openaccess@qub.ac.uk. 


\title{
Perceived Control and Quality of Life among Recipients of Implantable Cardioverter Defibrillator
}

\begin{abstract}
Background: Perceived control is strongly associated with health-related quality of life (HRQOL) among patients with chronic conditions, and it is possible to increase perceived control with appropriate intervention. Little is known about the relationship between perceived control and HRQOL in implantable cardioverter defibrillator (ICD) recipients.

Objectives: To determine the relationship of perceived control with quality of life (QOL) in ICD recipients and to determine predictors of perceived control in this population.

Methods: A total of 263 ICD recipients (63\% male, age $61 \pm 14$ years) completed the Control Attitude Scale-Revised to measure perceived control and completed self-reported measures on potential correlates of perceived control (i.e., depressive symptoms, anxiety, social support, and ICD concerns). The EuroQol-5D was used to measure HRQOL. Regression analysis was used to determine predictors of perceived control and its relationship to HRQOL, controlling for covariates.
\end{abstract}

Results: Lower perceived control $(\beta=0.30, p<.01)$, and higher levels of depression $(\beta=-0.30$, $p<.01)$ and anxiety $(\beta=-0.18, p<.05)$ predicted lower levels of HRQOL. Higher anxiety $(\beta=-$ $0.17, p<.05)$, higher depression $(\beta=-0.23, p<.05)$, lower social support $(\beta=0.26, p<.01)$, and higher ICD-related concerns $(\beta=-0.16, p<.05)$ independently predicted lower perceived control.

Conclusions: Interventions targeting patients' ICD concerns and psychosocial factors before, and continuing after, ICD insertion are needed to improve ICD recipients' perceived control and, in turn, their HRQOL in ICD recipients.

Keywords: Implantable Cardioverter Defibrillator; Quality of life; Perceived Control 


\section{Introduction}

The implantable cardioverter defibrillator (ICD) is standard treatment for life-threatening ventricular-arrhythmias and prevention of sudden cardiac death. ${ }^{1}$ Although the ICD has reduced mortality, ${ }^{2-4}$ patients' psychological responses, and adaptation to ICD implant are not simple. Patients' lives change after ICD implantation, ${ }^{5,6}$ and ICD recipients often are overwhelmed and live with fears related to the unpredictability of ICD shocks and the possibility of device failure..$^{7,8}$

Feelings of fear and uncertainty can reduce confidence and lead to decreased engagement in social and leisure activities. ${ }^{9,10}$ These changes in lifestyle can lead to anxiety and depressive symptoms, feelings of powerlessness and loss of control. ${ }^{7,11}$ About one-quarter of ICD recipients experience symptoms of anxiety and/or depression that result in decreased health-related quality of life (HRQOL). ${ }^{6,12,13}$ Psychological distress and impaired HRQOL are associated with adverse outcomes, such as increased rates of sustained lethal arrhythmias and higher risk of sudden cardiac death. ${ }^{14-18}$ In order to develop of strategies to improve patients' HRQOL, it is paramount to identify factors underlying and influencing HRQOL in ICD recipients.

Perceived control - the belief that one is able to cope with negative events, exert control over one's life and health, and achieve positive outcomes - is essential to successful adaptation to stressful events and improvement in HRQOL among patients with chronic cardiac diseases. ${ }^{19-21}$ A positive relationship between perceived control and HRQOL was found in heart failure (HF) patients and among female heart transplant recipients. ${ }^{22}$ However, predictors of perceived control and its relationship with HRQOL have not been studied in ICD recipients. Therefore, the aims of this study were to: 1) determine whether perceived control is an independent predictor of HRQOL in ICD recipients; and 2) identify predictors of perceived control in ICD recipients. 


\section{Methods}

\section{Design}

This cross-sectional study involved ICD recipients recruited from the United States and Australia. Before conducting the study, the appropriate institutional review board approvals were obtained from the two largest universities and two tertiary hospitals in Kentucky, United States (13-0993; 13.0666) and one university in Melbourne, Australia (215/15; 42-2015; 2015-165R). Data were collected between July 2015 and July 2016.

\section{Participants}

Participants were recruited from outpatient cardiology clinics located in four regional tertiary care referral facilities. Patients were invited to participate if they had an ICD inserted more than a year ago and were able to speak and read in English. Patients who had severe cognitive impairment, coexisting terminal illness or a left ventricular assist device were excluded. Further, patients who were on the heart transplant waiting list or institutionalized in nursing homes were excluded.

\section{Procedures}

Participants were referred to the study by nurses working at the recruitment sites. A trained Research Assistant (RA) approached the potential subjects who were attending the clinic for routine ICD follow-up visits, screened them for eligibility, explained the purpose and details of the study, invited them to participate, and obtained written informed consent. Participants were provided with a signed copy of their consent form and a hard copy of the study questionnaires with a prepaid addressed envelope to take the questionnaires home, complete

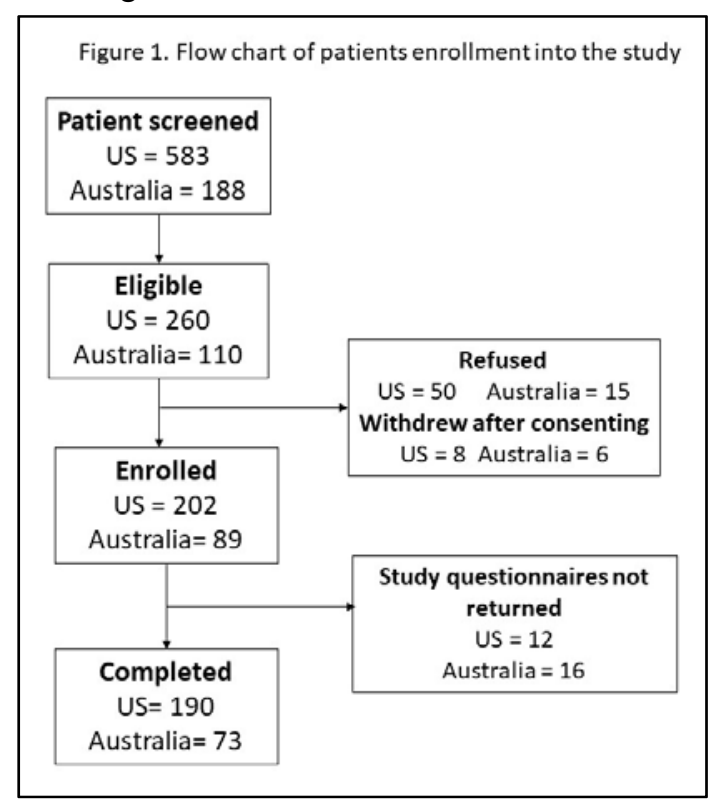
and return at their convenience. Participants also had the option to complete the questionnaires 
online using the REDCap system or in the clinic if they chose to do so. More than $90 \%$ of participants chose to take the questionnaires home to complete and return by mail. Participants' response rate was $82 \%$ in Australia and $94 \%$ in the United States (Figure 1).

\section{Measures}

Sociodemographic and clinical characteristics. Data about age, gender, ethnicity, level of education, and whether recipients had received ICD shocks were collected using the study survey.

Health-related quality of life (HRQOL). HRQOL was assessed using the EuroQol 5D (EQ-5D) self-report questionnaire. ${ }^{23}$ The EQ-5D consists of five dimensions of health: mobility, self-care, usual activities, pain/discomfort, and anxiety/depression. Each dimension is rated on 3 levels of severity $(1=$ none, $2=$ moderate and $3=$ extreme problems $)$. Scores on the EQ-5D index value can range from 1.0 (best quality of life), to -0.11 (worst quality of life). Reliability and validity of the instrument have been supported in patients with cardiovascular disease ${ }^{24}$ and in medical patients with HIV, chronic hepatic diseases, and cancer. ${ }^{25-28}$

Perceived control. Perceived control was assessed using the Control Attitudes Scale-Revised (CAS-R). ${ }^{29}$ The CAS-R consists of 8 items rated on a 1 (totally disagree) to 5 (totally agree) scale. Total scores can range from 8 to 40 and lower scores reflect lower levels of perceived control. The reliability and validity of the CAS-R have been supported in patients with cardiac diseases. ${ }^{29}$ In the current study, Cronbach's alpha was 0.87 .

Social support. Social support was assessed using the Multidimensional Perceived Social Support Scale (MPSSS). ${ }^{30}$ The MPSSS assesses one's perception of levels of social support received from family, friends, or/and significant others. The MPSSS is a 12-item instrument rated on a 7-point scale from 1 (very strongly disagree with the item) to 7 (very strongly agree). Individual item ratings are added to form a total score ranging from 12 to 84 ; higher total scores indicate higher levels of perceived social support. The validity and reliability of the MPSSS have 
been supported in healthy subjects ${ }^{31,32}$ and in patients with HF and coronary heart disease. ${ }^{30}$ In the current study, Cronbach's alpha was 0.97 .

Anxiety and depression. Anxiety and depression symptoms were assessed using the Hospital Anxiety and Depression Scale (HADS). ${ }^{33}$ The HADS is composed of 14 items that result in two subscales, anxiety and depression. Each item is rated on a 4-point Likert scale from 0 to 3. Responses are summed to form a total score ranging from 0 to 21 for both anxiety and depression; higher scores indicate more symptoms of anxiety or depression. A cut off point of 8 on both subscales has been recommended to identify patients with clinical symptoms of anxiety and depression. ${ }^{33}$ The reliability and validity of the HADS have been supported in somatic, psychiatric, medical, cardiac, and primary care patients and in the general population. ${ }^{34-36}$ In the current study, Cronbach's alpha was 0.79 .

ICD-related concerns. ICD-related concerns were assessed using the ICD Concerns (ICDC) questionnaire. ${ }^{37}$ The ICDC questionnaire consists of 8 self-report items rated on a 5-point Likert scale from 0 (not at all) to 4 (very much so); higher scores indicate a greater number of concerns. Reliability and validity of the ICDC have been supported. ${ }^{37,38}$ In the current study, Cronbach's alpha was 0.94 .

ICD knowledge. ICD knowledge was assessed using the End-of-Life issues in ICD (EOL-ICD) Questionnaire. ${ }^{39}$ The EOL-ICD is a self-rated questionnaire, consisting of three subscales that measure experiences (10 items), attitudes (18 items), and knowledge (11 items) of EOL or related issues in ICD patients. The 11 items in the knowledge subscale measure ethical aspects of treatment ( 3 items), how the ICD works ( 2 items), and the significance of ICD deactivation (6 items). Each item of the knowledge subscale is scored as 0 (False) or 1 (True). Responses are summed to form a total score ranging from 0 to 11 . The EOL-ICD Questionnaire has demonstrated sound psychometric properties. ${ }^{39}$ In the current study, the knowledge subscale Cronbach's alpha was 0.78 . 


\section{Data analysis}

Data were analyzed using SPSS for Windows (version 24.0, SPSS, Inc., Chicago, IL); an alpha level of .05 was used throughout. Descriptive statistics, including means and standard deviations or percentages, were used to summarize socio-demographic and clinical characteristics, depending on the level of measurement of the variables. Sociodemographic and HRQOL of ICD recipients in US versus Australia were compared using chi-square tests or independent sample T-tests, as appropriate.

Linear regression modeling was used to examine the relationship between perceived control and HRQOL. A univariate linear regression model was used to examine the association between perceived control and HRQOL. Hierarchical multiple regression with enter method was used to determine whether perceived control predicts HRQOL, controlling for covariates. The EQ-5D mean index value (dependent variable) was entered in the model as a continuous variable. Predictors were entered in blocks. The first block included the sociodemographic, clinical characteristics (age, gender, and whether recipients experienced ICD shocks), and psychosocial factors (anxiety, depression, ICDC concerns, and social support). The second block included perceived control. ${ }^{40,41}$ The third block included all 2-way interactions between perceived control and covariates to explore moderation effects. None were significant, so they were removed from the model and results from the first 2 blocks were presented in Table 2.

Dimensions of the EQ-5D (i.e., mobility, self-care, usual activities, pain, and anxiety/depression) reflects the HRQOL aspects of physical functioning, social functioning and mental health. In addition to the index value, results of the EQ-5D can be presented as a health profile presenting proportion of reported problems/no problems in each dimension in tabulated form. After determining whether perceived control predicts the overall HRQOL using the index value, we used five separate binary logistic regression models to examine whether perceived control predicts each of the HRQOL dimensions in the EQ-5D questionnaire (i.e., pain, mobility, self-care, usual activity, and anxiety/depression), controlling for covariates. Gender and age 
were included in all models as they were considered of theoretical interest despite being nonsignificant predictors of HRQOL in this cohort of ICD recipients. The outcome variable in each dimension of EQ-5D was dichotomized to "No problem/Problem".

Hierarchical multiple linear regression analysis was used to determine predictors of perceived control, after adjusting for covariates. Predictors were identified from the literature and entered in two blocks. The first block included the sociodemographic and clinical characteristics (i.e., age, gender, and whether recipients experienced ICD shocks). The second block included the psychosocial (i.e., anxiety, depression, ICDC concerns, and social support) factors and ICD knowledge score. These grouped predictors were entered in blocks to determine the contribution of each group to the explanation of the variance in perceived control. Model assumptions were evaluated and were not violated.

\section{Results}

\section{Sample characteristic}

The study sample consisted of 263 ICD recipients (190 participants from US and 73 participants from Australia; Table 1). The mean age of participants was $61 \pm 14$ years. Most of the participants were men and were either married or living with someone. The majority of participants (85\%) self-identified as a Caucasian. More than a third of the study sample had a history of receiving an ICD shock. Using the reported scores of HADS ( $\geq 8), 25 \%$ of participants in this study had symptoms of anxiety and $18 \%$ depression.

Differences between participants recruited from US and Australia. Participants recruited from Australia were all Caucasian (100\%) and reported slightly higher level of HRQOL $(0.84 \pm 0.16)$ than those recruited from US $(0.79 \pm 0.18)$. No other significant differences on sociodemographic or clinical variables between the two study sites were found. Therefore, we combined all patients' data collected from the US and Australia to analyze our specific aims.

Relationship between perceived control and HRQOL. In univariate linear regression, perceived control explained $13 \%$ of the variance in $\mathrm{HRQOL}(\beta=0.37 ; p$-value $<.001)$. In multiple 
linear regression analysis (Table 2), the model explained $27 \%$ of the variance in $H R Q O L\left[R^{2}\right.$ $=0.27, F(1,191)=8.82, p<.01]$. Higher levels of depression $(\beta=-0.30, p<.01)$, anxiety $(\beta=-$ $0.18, p<.05)$, and lower perceived control $(\beta=0.30, p<.01)$ predicted lower levels of HRQOL. Adding perceived control to the model explained an additional $7 \%$ of the variance in $\mathrm{HRQOL}$. Logistic regression analysis was then performed to assess whether perceived control predicts of each dimension of HRQOL, while controlling for covariates (age, gender, receiving shock). Five separate models were developed for each of the EQ-D5 outcomes (Table 3). Mobility. Patients with higher level of depression were 5.56 times more likely to have problems with mobility, while patients with low perceived control were 2 times more likely to report problems with mobility.

Self-care. Our model became insignificant when we included ICD concerns as a covariate, implying presence of mediating relationships between the model variables. Therefore, we excluded ICD concerns from our model. Males were about 2.5 times more likely to report problems with self-care than females. Patients with low perceived control were almost 4 times more likely to report problems with self-care.

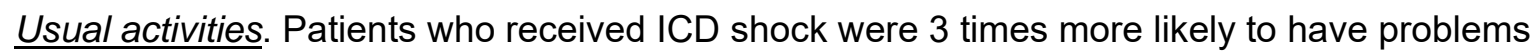
with performing usual activities. Patients with higher level of depression were 4.66 times more likely to have problems with performing usual activities, while patients with low perceived control were 2 times more likely to report problems with performing usual activities.

$\underline{\text { Pain. }}$. Patients with higher level of anxiety were about 11.4 times more likely to report problems with pain, while those patients with lower perceived control were 3 times more likely to report pain.

Anxiety/depression. Anxiety and depression measured using HADS were not included as covariates in this model as co-variables because our outcome was anxiety and depression measured using EQ-5D scale. Patients with lower perceived control were 3 times more likely to report problems with anxiety and depression. 
Predictors of perceived control. In the whole sample, the model explained $30 \%$ of the variance in perceived control $(p<0.001)$, with $28 \%$ of the variance explained by the psychosocial variables $(p<0.001)$. Higher anxiety $(\beta=-0.17, p<.05)$, higher depression $(\beta=-$ $0.23, p<.05)$, lower social support $(\beta=-0.26, p 0<.01)$, and higher ICD concerns scores $(\beta=-$ $0.16, p<.05$ ) were independently associated with lower levels of perceived control (Table 4).

\section{Discussion}

The main finding of our study was that perceived control predicted overall HRQOL and greater prevalence of self-reported problems in every dimension of HRQOL, (i.e. mobility, self-care, usual activity, pain, and symptoms of anxiety and/or depression). The addition of perceived control explained $7 \%$ more variance in $\mathrm{HRQOL}$ than a model containing only demographic, clinical and psychological covariates. These findings imply the importance of targeting perceived control as well as psychological variables to improve ICD recipients' HRQOL. Our findings are consistent with prior HF studies, ${ }^{40,41}$ in which perceived control was significantly associated with HRQOL, controlling for sociodemographic, clinical, and psychological factors. However, this is the first study to assess the underlying importance of perceived control amongst ICD recipients and therefore makes a unique contribution to the literature.

While psychological distress in ICD recipients has been reported in multiple studies, ${ }^{7,}, 13$, 42 prior studies of HRQOL in ICD recipients mostly addressed sequelae of anxiety, depression and ICD shocks. ICD recipients who received shocks revealed higher levels of anxiety and depression, decreased adaptation to living with the device, and worse HRQOL.43-47 Therefore, this is the first study to consider perceived control and identify the key role it plays in improving $\mathrm{HRQOL}$ in patients with cardiac diseases. Our model explained $27 \%$ of the variance in $\mathrm{HRQOL}$. This is perhaps not a surprising finding given the effect of uncontrolled confounders in observational studies. In addition, we did not measure other important predictors that may affect HRQOL in ICD recipients, such as body image concerns, ${ }^{48}$ personality type,${ }^{49}$ influence on the relationship with one's partner, ${ }^{50}$ sexual activity, ${ }^{51}$ spiritual well-being, ${ }^{52}$ and driving 
restrictions. ${ }^{53}$ Although we did not directly examine the mechanism through which perceived control is associated with $\mathrm{HRQOL}$ in ICD recipients, we hypothesized that perceived control affects HRQOL through its impact on psychological status, symptoms and functional status. ${ }^{19,22,}$ 54-56 However, It is also possible that HRQOL affects perceived control, but we could not examine this relationship due to the cross-sectional study design. In support of this hypothesis, we found that patients with lower perceived control reported more problems with mobility, selfcare, usual activity, pain, anxiety and depression. Compared to patients with higher perceived control, Dracup et al. ${ }^{19}$ found that HF patients with lower perceived control walked shorter distances by 211 feet (1,241 vs. 1,452 feet) on the 6-minute walk and had higher emotional distress. Similarly, among patients with HF and other cardiac diseases, Moser et al. ${ }^{20,29}$ and Heo et al. ${ }^{41}$ found that patients with lower perceived control had higher levels of depressive symptoms compared to those with higher perceived control. In other studies, ${ }^{19,22,55,56}$ lower level of perceived control was associated with worse HRQOL and more reported symptoms of anxiety and depression. Doerfler et al. ${ }^{57}$ reported that after recent myocardial infarction, patients with lower perceived control had higher scores of posttraumatic stress disorder symptoms.

Numerous studies and reviews ${ }^{13,37,58-61}$ have shown an association between ICD shocks, age, gender, social support, ICD concerns, and HRQOL. ICD recipients who received shocks have been shown to exhibit higher levels of anxiety and depression, lower adaptation to living with the device, decreased physical and mental well-being, and worse HRQOL. ${ }^{43-47}$ In some studies, younger age, female gender, and lack of social support have also been associated with higher anxiety, depression and worse HRQOL. ${ }^{45,58,61-63}$ In contrast, other studies have found no correlation between patient's age, experiencing ICD shocks, and HRQOL. ${ }^{64-67}$ Discrepancies in results are most likely due to heterogeneity between study populations, such as time since ICD implantation, sample size and instruments used in measuring HRQOL constructs. ${ }^{42,46,58,59}$ Results of our study mostly parallel the findings that 
HRQOL was not correlated with ICD shocks, age, or social support, possibly because our participants had their ICDs implanted at least a year before joining the study. Previous studies showed that shock-related anxiety tends to lessen over time post implantation. ${ }^{42,58}$ However, to detect changes in HRQOL over time, further research is needed. In this study, ICD shocks were only correlated with pain, which is typically reported by ICD recipients.

The findings of the current study provide valuable information on factors affecting perceived control in ICD recipients. A significant proportion of our participants reported clinical symptoms of anxiety $(25 \%)$ and/or depression (18\%) which was consistent with other studies. ${ }^{12}$, 42 In a systematic review from 2011, anxiety occurred in 15-49\% of ICD recipients during 6-12 months post implant; while depression occurred in $10-33 \%$ of recipients. ${ }^{42}$ Lower level of perceived control was predicted by higher levels of anxiety, depression, ICD concerns; and lower level of social support. Knowledge about ICD function was not related to perceived control. Similarly, in a HF study by Heo et al ${ }^{41}$ knowledge was not associated with perceived control in multivariate regression analysis. These findings imply that delivering interventions such as psycho-educational counseling are more important than delivering simple information to improve perceived control and, in turn, HRQOL in this population. ${ }^{68-70}$ Tullmann et al. $^{70}$ delivered a structured education and counseling intervention to 115 patients with myocardial infarction, which resulted in higher perceived control and knowledge compared to patients in the control group. In asthma patients, ${ }^{69}$ perceived control of asthma and quality of life significantly improved after completing the behavior modification-based adult asthma education program.

Current education and information materials given to ICD patients generally focus on device-technical performance and patient's biophysical life as opposed to patients' perceived limitations to their own lifestyle, despite the fact that emotional, biophysical, intellectual, sociocultural, and spiritual life are all affected by ICD implantation. ${ }^{71}$ A review of 12 studies ${ }^{8}$ examining psychological adaptation in ICD recipients showed that recipients had fears of shock, isolation, driving restrictions, ICD failure, and fear of sexual or physical activity that may 
result in receiving shock. A conversation between patients and their providers about expected limitations and changes in physical, emotional and social activities; $8,45,72,73$ as well as how to rapidly resume daily activities is highly needed and should be undertaken before and after ICD implantation. ${ }^{74}, 75$ If such limitations are not addressed early, patients may avoid the activities they used to enjoy due to fear of ICD triggering an electric shock in connection to certain activities. ${ }^{10}$ With avoidance behaviors, recipients' self-control decreases, HRQOL worsens and substantial proportion of patients will feel anxious and depressed. ${ }^{8,10,73,75}$ Heo et al. ${ }^{21}$ asked $20 \mathrm{HF}$ patients to define $\mathrm{HRQOL}$ and reported that a good HRQOL meant being able to perform desired physical and social activities of daily livings, pursue happiness and have fulfilling relationships with others. Patients' definitions reflected their active efforts to have a good HRQOL, a sense of control appeared to be the core component for having a good HRQOL.

Maintaining a good quality of life, psychosocial recovery and adaptation to living with chronic cardiac illness depends more on psychological than on physical factors. ${ }^{20}$ Therefore, the approach to treating ICD recipients should be holistic and their families should be included to help them incorporate changes into their lifestyle. ${ }^{59,76,77}$

Depression is common in ICD recipients. ${ }^{12,13,42,46,58}$ Guidelines exist for the screening and treatment of depression in patients with coronary heart diseases, ${ }^{78,79}$ but not in ICD recipients. Given the impact of depression on outcomes in ICD recipients, ${ }^{80}$ clinicians should consider screening ICD recipients for depression during their follow-up visits and refer those who screen or report positive to psychiatric services for further assessment and appropriate therapies. For example, cognitive behavioral therapy (CBT) may contribute to reducing depression and anxiety in this population. In a small pilot study, ${ }^{81} 22$ ICD recipients were randomized into a comprehensive 12-week cognitive behavioral rehabilitation program that incorporated both exercise and psychological training $(n=12)$ or no treatment group $(n=10)$. The rehabilitation program group had significantly less anxiety and depression and better HRQOL. Kohn et al. ${ }^{82}$ conducted a randomized controlled trial of CBT $(n=25)$ versus usual 
care $(n=24)$ and found that CBT significantly decreased depression and anxiety, and increased overall adjustment for ICD, particularly in patients who had experienced ICD shocks. Despite the small number of participants involved in CBT trials targeting ICD recipients, statistically significant improvement in psychological and exercise ability outcomes were detected. This implies the importance of including CBT as a major component of cardiac rehabilitation program.

Summary and Conclusion. Lower level of perceived control and higher HADS score (indicating symptoms of depression and/or anxiety) amongst ICD recipients were strongly associated with worse HRQOL, controlling for demographic, clinical and other psychological factors. Perceived control was predicted by higher HADS score for anxiety, depression, by ICD concerns and lower level of social support. These results suggest that reducing psychosocial distress may be instrumental in improving perceived control and thereby increasing HRQOL in ICD recipients. Psycho-educational and counseling interventions are warranted to improve health outcomes in this population.

Future studies. The results of small pilot studies have shown that CBT had positive effects on levels of anxiety and depression in ICD recipients. ${ }^{81,82}$ Large-scale interventions focusing on CBT and psycho-educational programs that target psychosocial factors before and after ICD implantation are needed to identify its impact on symptoms of anxiety, depression and HRQOL. These studies should include larger sample size and longer follow-up times.

In this study, lower levels of perceived control were strongly associated with more reported problems in self-care, but this relationship became insignificant after controlling for ICD concerns. Further studies are needed to examine possible mediating relationship between ICD concerns, perceived control, self-care and HRQOL.

Limitations. There are limitations to note. 1) More than $70 \%$ of our participants were men, making comparisons of predictors of $\mathrm{HRQOL}$ and perceived control based on gender differences difficult. 2) Our sample participants were mainly Caucasian, which limits 
generalizability of the findings to minority population. 3) We used a cross-sectional design. Therefore, we were unable to assess any cause and effect relationship between perceived control and HRQOL. 4) The study variables including HRQOL, perceived control, depression and anxiety were measured using self-reported questionnaires, which may have resulted in bias depending on the emotional status the participants had while completing the questionnaire. However, using self-report measures is widely used in research.

Clinical Implications. Education is a critical strategy in empowering ICD recipients. Psychoeducational programs should be integrated as a major component of treatment in order to improve perceived control and, in turn, HRQOL in ICD recipients.

Acknowledgment. The authors disclosed receipt of the following financial support for this work: In the United States, the study was funded by XXX. In Australia, this study received funding from XXX. Information about funding resources is hided for confidentiality at this stage of manuscript review 


\section{References}

1. Finch NJ, Leman RB. Clinical trials update: Sudden cardiac death prevention by implantable device therapy. Critical care nursing clinics of North America. 2005;17:33-38, x

2. Greenberg H, Case RB, Moss AJ, Brown MW, Carroll ER, Andrews ML, Investigators M-I. Analysis of mortality events in the multicenter automatic defibrillator implantation trial (madit-ii). Journal of the American College of Cardiology. 2004;43:1459-1465

3. Bardy GH, Lee KL, Mark DB, Poole JE, Packer DL, Boineau R, Domanski M, Troutman C, Anderson J, Johnson G, McNulty SE, Clapp-Channing N, Davidson-Ray LD, Fraulo ES, Fishbein DP, Luceri RM, Ip JH, Sudden Cardiac Death in Heart Failure Trial I. Amiodarone or an implantable cardioverter-defibrillator for congestive heart failure. The New England journal of medicine. 2005;352:225-237

4. Moss AJ, Hall WJ, Cannom DS, Daubert JP, Higgins SL, Klein H, Levine JH, Saksena S, Waldo AL, Wilber D, Brown MW, Heo M. Improved survival with an implanted defibrillator in patients with coronary disease at high risk for ventricular arrhythmia. Multicenter automatic defibrillator implantation trial investigators. The New England journal of medicine. 1996;335:1933-1940

5. Eckert $\mathrm{M}$, Jones T. How does an implantable cardioverter defibrillator (icd) affect the lives of patients and their families? International journal of nursing practice. 2002;8:152-157

6. Heller SS, Ormont MA, Lidagoster L, Sciacca RR, Steinberg S. Psychosocial outcome after icd implantation: A current perspective. Pacing and clinical electrophysiology : PACE. 1998;21:12071215

7. Sears SF, Jr., Todaro JF, Lewis TS, Sotile W, Conti JB. Examining the psychosocial impact of implantable cardioverter defibrillators: A literature review. Clinical cardiology. 1999;22:481-489

8. Zayac S, Finch N. Recipients' of implanted cardioverter-defibrillators actual and perceived adaptation: A review of the literature. Journal of the American Academy of Nurse Practitioners. 2009;21:549-556

9. Herrmann C, von zur Muhen F, Schaumann A, Buss U, Kemper S, Wantzen C, Gonska BD. Standardized assessment of psychological well-being and quality-of-life in patients with implanted defibrillators. Pacing and clinical electrophysiology : PACE. 1997;20:95-103

10. Lemon J, Edelman S, Kirkness A. Avoidance behaviors in patients with implantable cardioverter defibrillators. Heart \& lung : the journal of critical care. 2004;33:176-182

11. Groeneveld PW, Matta MA, Suh JJ, Heidenreich PA, Shea JA. Costs and quality-of-life effects of implantable cardioverter-defibrillators. The American journal of cardiology. 2006;98:1409-1415

12. Freedenberg $V$, Thomas SA, Friedmann E. Anxiety and depression in implanted cardioverterdefibrillator recipients and heart failure: A review. Heart failure clinics. 2011;7:59-68

13. Sears SF, Jr., Conti JB. Quality of life and psychological functioning of icd patients. Heart. 2002;87:488-493

14. Dunbar SB, Kimble LP, Jenkins LS, Hawthorne M, Dudley W, Slemmons M, Langberg JJ. Association of mood disturbance and arrhythmia events in patients after cardioverter defibrillator implantation. Depression and anxiety. 1999;9:163-168

15. Culic V, Silic N, Miric D. Triggering of ventricular ectopic beats by emotional, physical, and meteorologic stress: Role of age, sex, medications, and chronic risk factors. Croatian medical journal. 2005;46:894-906

16. Iyer HV. Emotional stress and sudden death--the role of cathecholaminergic polymorphic ventricular tachycardia. European journal of internal medicine. 2009;20:e160

17. Lampert R, Joska T, Burg MM, Batsford WP, McPherson CA, Jain D. Emotional and physical precipitants of ventricular arrhythmia. Circulation. 2002;106:1800-1805 
18. Rashba EJ. Anger management may save your life new insights into emotional precipitants of ventricular arrhythmias. Journal of the American College of Cardiology. 2009;53:779-781

19. Dracup K, Westlake C, Erickson VS, Moser DK, Caldwell ML, Hamilton MA. Perceived control reduces emotional stress in patients with heart failure. The Journal of heart and lung transplantation : the official publication of the International Society for Heart Transplantation. 2003;22:90-93

20. Moser DK, Dracup K. Psychosocial recovery from a cardiac event: The influence of perceived control. Heart \& lung : the journal of critical care. 1995;24:273-280

21. Heo S, Lennie TA, Okoli C, Moser DK. Quality of life in patients with heart failure: Ask the patients. Heart \& lung : the journal of critical care. 2009;38:100-108

22. Evangelista LS, Moser D, Dracup K, Doering L, Kobashigawa J. Functional status and perceived control influence quality of life in female heart transplant recipients. The Journal of heart and lung transplantation : the official publication of the International Society for Heart Transplantation. 2004;23:360-367

23. Euroqol--a new facility for the measurement of health-related quality of life. The euroqol group. Health Policy. 1990;16:199-208

24. Dyer MT, Goldsmith KA, Sharples LS, Buxton MJ. A review of health utilities using the eq- $5 \mathrm{~d}$ in studies of cardiovascular disease. Health Qual Life Outcomes. 2010;8:13

25. Wu AW, Jacobson KL, Frick KD, Clark R, Revicki DA, Freedberg KA, Scott-Lennox J, Feinberg J. Validity and responsiveness of the euroqol as a measure of health-related quality of life in people enrolled in an aids clinical trial. Qual Life Res. 2002;11:273-282

26. Kim SH, Hwang JS, Kim TW, Hong YS, Jo MW. Validity and reliability of the eq-5d for cancer patients in korea. Support Care Cancer. 2012;20:3155-3160

27. Scalone L, Ciampichini R, Fagiuoli S, Gardini I, Fusco F, Gaeta L, Del Prete A, Cesana G, Mantovani LG. Comparing the performance of the standard eq- $5 \mathrm{~d} 3 \mathrm{l}$ with the new version eq- $5 \mathrm{~d} 5 \mathrm{l}$ in patients with chronic hepatic diseases. Qual Life Res. 2013;22:1707-1716

28. Tran BX, Ohinmaa A, Nguyen LT. Quality of life profile and psychometric properties of the eq-5d5 I in hiv/aids patients. Health Qual Life Outcomes. 2012;10:132

29. Moser DK, Riegel B, McKinley S, Doering LV, Meischke H, Heo S, Lennie TA, Dracup K. The control attitudes scale-revised: Psychometric evaluation in three groups of patients with cardiac illness. Nursing research. 2009;58:42-51

30. Blumenthal JA, Burg MM, Barefoot J, Williams RB, Haney T, Zimet G. Social support, type a behavior, and coronary artery disease. Psychosom Med. 1987;49:331-340

31. Zimet GD, Powell SS, Farley GK, Werkman S, Berkoff KA. Psychometric characteristics of the multidimensional scale of perceived social support. J Pers Assess. 1990;55:610-617

32. Canty-Mitchell J, Zimet GD. Psychometric properties of the multidimensional scale of perceived social support in urban adolescents. Am J Community Psychol. 2000;28:391-400

33. Zigmond AS, Snaith RP. The hospital anxiety and depression scale. Acta psychiatrica Scandinavica. 1983;67:361-370

34. Spinhoven P, Ormel J, Sloekers PP, Kempen GI, Speckens AE, Van Hemert AM. A validation study of the hospital anxiety and depression scale (hads) in different groups of dutch subjects. Psychol Med. 1997;27:363-370

35. Bjelland I, Dahl AA, Haug TT, Neckelmann D. The validity of the hospital anxiety and depression scale. An updated literature review. J Psychosom Res. 2002;52:69-77

36. Brennan C, Worrall-Davies A, McMillan D, Gilbody S, House A. The hospital anxiety and depression scale: A diagnostic meta-analysis of case-finding ability. J Psychosom Res. 2010;69:371-378 
37. Frizelle DJ, Lewin B, Kaye G, Moniz-Cook ED. Development of a measure of the concerns held by people with implanted cardioverter defibrillators: The icdc. British journal of health psychology. 2006;11:293-301

38. Pedersen SS, van Domburg RT, Theuns DA, Jordaens L, Erdman RA. Concerns about the implantable cardioverter defibrillator: A determinant of anxiety and depressive symptoms independent of experienced shocks. Am Heart J. 2005;149:664-669

39. Thylén I, Wenemark M, Fluur C, Strömberg A, Bolse K, Årestedt K. Development and evaluation of the eol-icdq as a measure of experiences, attitudes and knowledge in end-of-life in patients living with an implantable cardioverter defibrillator. European J Cardiovascular Nursing. 2014;13:142-151

40. Banerjee T, Lee KS, Browning SR, Hopenhayn C, Westneat S, Biddle MJ, Arslanian-Engoren C, Eastwood JA, Mudd G, Moser DK. Limited association between perceived control and healthrelated quality of life in patients with heart failure. The Journal of cardiovascular nursing. 2014;29:227-231

41. Heo S, Lennie TA, Pressler SJ, Dunbar SB, Chung ML, Moser DK. Factors associated with perceived control and the relationship to quality of life in patients with heart failure. European journal of cardiovascular nursing : journal of the Working Group on Cardiovascular Nursing of the European Society of Cardiology. 2015;14:137-144

42. Magyar-Russell G, Thombs BD, Cai JX, Baveja T, Kuhl EA, Singh PP, Montenegro Braga Barroso M, Arthurs E, Roseman M, Amin N, Marine JE, Ziegelstein RC. The prevalence of anxiety and depression in adults with implantable cardioverter defibrillators: A systematic review. J Psychosom Res. 2011;71:223-231

43. Kamphuis HC, de Leeuw JR, Derksen R, Hauer RN, Winnubst JA. Implantable cardioverter defibrillator recipients: Quality of life in recipients with and without icd shock delivery: A prospective study. Europace : European pacing, arrhythmias, and cardiac electrophysiology: journal of the working groups on cardiac pacing, arrhythmias, and cardiac cellular electrophysiology of the European Society of Cardiology. 2003;5:381-389

44. Kamphuis HC, De Leeuw JR, Derksen R, Hauer R, Winnubst JA. A 12-month quality of life assessment of cardiac arrest survivors treated with or without an implantable cardioverter defibrillator. Europace : European pacing, arrhythmias, and cardiac electrophysiology : journal of the working groups on cardiac pacing, arrhythmias, and cardiac cellular electrophysiology of the European Society of Cardiology. 2002;4:417-425

45. Schron EB, Exner DV, Yao Q, Jenkins LS, Steinberg JS, Cook JR, Kutalek SP, Friedman PL, Bubien $\mathrm{RS}$, Page RL, Powell J. Quality of life in the antiarrhythmics versus implantable defibrillators trial: Impact of therapy and influence of adverse symptoms and defibrillator shocks. Circulation. 2002;105:589-594

46. Carroll DL, Hamilton GA. Quality of life in implanted cardioverter defibrillator recipients: The impact of a device shock. Heart \& lung : the journal of critical care. 2005;34:169-178

47. Jacq F, Foulldrin G, Savoure A, Anselme F, Baguelin-Pinaud A, Cribier A, Thibaut F. A comparison of anxiety, depression and quality of life between device shock and nonshock groups in implantable cardioverter defibrillator recipients. General hospital psychiatry. 2009;31:266-273

48. Frydensberg Vivi SV. Body image concerns in patients with an implantable cardioverter defibrillator: A scoping review. Pacing and Clinical Electrophysiology. 2018;41:1235-1260

49. Habibovic Mirela M. Gender disparities in anxiety and quality of life in patients with an implantable cardioverter-defibrillator. Europace : European pacing, arrhythmias, and cardiac electrophysiology : journal of the working groups on cardiac pacing, arrhythmias, and cardiac cellular electrophysiology of the European Society of Cardiology.13:1723-1730 
50. Morken Ingvild Margreta IM. Reconstructing unpredictability: Experiences of living with an implantable cardioverter defibrillator over time. Journal of clinical nursing.19:537-546

51. Steinke Elaine EE. Sexual concerns and educational needs after an implantable cardioverter defibrillator. Heart and Lung. 2005;34:299-308

52. Salmoirago-Blotcher Elena E. Spiritual well-being may buffer psychological distress in patients with implantable cardioverter defibrillators (icd). Journal of Evidence-Based Complementary and Alternative Medicine. 2012;17:148-154

53. Johansson Ingela I. Experiences of driving and driving restrictions in recipients with an implantable cardioverter defibrillator--the patient perspective. Journal of Cardiovascular Nursing. 2010;25:1

54. Zilioli S, Imami L, Slatcher RB. Socioeconomic status, perceived control, diurnal cortisol, and physical symptoms: A moderated mediation model. Psychoneuroendocrinology. 2017;75:36-43

55. Moser DK, Dracup K. Role of spousal anxiety and depression in patients' psychosocial recovery after a cardiac event. Psychosom Med. 2004;66:527-532

56. Bailis DS, Segall A, Mahon MJ, Chipperfield JG, Dunn EM. Perceived control in relation to socioeconomic and behavioral resources for health. Social science \& medicine. 2001;52:16611676

57. Doerfler LA, Paraskos JA, Piniarski L. Relationship of quality of life and perceived control with posttraumatic stress disorder symptoms 3 to 6 months after myocardial infarction. Journal of cardiopulmonary rehabilitation. 2005;25:166-172

58. Thomas SA, Friedmann E, Kao CW, Inguito P, Metcalf M, Kelley FJ, Gottlieb SS. Quality of life and psychological status of patients with implantable cardioverter defibrillators. American journal of critical care : an official publication, American Association of Critical-Care Nurses. 2006;15:389398

59. Thomas SA, Friedmann E, Kelley FJ. Living with an implantable cardioverter-defibrillator: A review of the current literature related to psychosocial factors. AACN clinical issues.

2001;12:156-163

60. Hegel MT, Griegel LE, Black C, Goulden L, Ozahowski T. Anxiety and depression in patients receiving implanted cardioverter-defibrillators: A longitudinal investigation. International journal of psychiatry in medicine. 1997;27:57-69

61. Miller JL, Thylen I, Moser DK. Gender disparities in symptoms of anxiety, depression, and quality of life in defibrillator recipients. Pacing and clinical electrophysiology : PACE. 2016;39:149-159

62. Wallace RL, Sears SF, Jr., Lewis TS, Griffis JT, Curtis A, Conti JB. Predictors of quality of life in long-term recipients of implantable cardioverter defibrillators. Journal of cardiopulmonary rehabilitation. 2002;22:278-281

63. Spindler H, Johansen JB, Andersen K, Mortensen P, Pedersen SS. Gender differences in anxiety and concerns about the cardioverter defibrillator. Pacing and clinical electrophysiology: PACE. 2009;32:614-621

64. Czosek RJ, Bonney WJ, Cassedy A, Mah DY, Tanel RE, Imundo JR, Singh AK, Cohen MI, Miyake CY, Fawley K, Marino BS. Impact of cardiac devices on the quality of life in pediatric patients. Circulation. Arrhythmia and electrophysiology. 2012;5:1064-1072

65. Passman R, Subacius H, Ruo B, Schaechter A, Howard A, Sears SF, Kadish A. Implantable cardioverter defibrillators and quality of life: Results from the defibrillators in nonischemic cardiomyopathy treatment evaluation study. Archives of internal medicine. 2007;167:2226-2232

66. Hsu J, Uratsu C, Truman A, Quesenberry C, McDonald KM, Hlatky MA, Selby J. Life after a ventricular arrhythmia. Am Heart J. 2002;144:404-412

67. Newall EG, Lever NA, Prasad S, Hornabrook C, Larsen PD. Psychological implications of icd implantation in a new zealand population. Europace : European pacing, arrhythmias, and cardiac 
electrophysiology : journal of the working groups on cardiac pacing, arrhythmias, and cardiac cellular electrophysiology of the European Society of Cardiology. 2007;9:20-24

68. Moser DK, Dracup K. Impact of cardiopulmonary resuscitation training on perceived control in spouses of recovering cardiac patients. Research in nursing \& health. 2000;23:270-278

69. Olajos-Clow J, Costello E, Lougheed MD. Perceived control and quality of life in asthma: Impact of asthma education. The Journal of asthma : official journal of the Association for the Care of Asthma. 2005;42:751-756

70. Tullmann DF, Haugh KH, Dracup KA, Bourguignon C. A randomized controlled trial to reduce delay in older adults seeking help for symptoms of acute myocardial infarction. Research in nursing \& health. 2007;30:485-497

71. Flemme I, Bolse K, Ivarsson A, Jinhage BM, Sandstedt B, Edvardsson N, Fridlund B. Life situation of patients with an implantable cardioverter defibrillator: A descriptive longitudinal study. Journal of clinical nursing. 2001;10:563-572

72. Reiffel JA, Dizon J. Cardiology patient page. The implantable cardioverter-defibrillator: Patient perspective. Circulation. 2002;105:1022-1024

73. Kamphuis M, Zwinderman KH, Vogels T, Vliegen HW, Kamphuis RP, Ottenkamp J, VerlooveVanhorick SP, Bruil J. A cardiac-specific health-related quality of life module for young adults with congenital heart disease: Development and validation. Qual Life Res. 2004;13:735-745

74. Tagney J. Implantable cardioverter defibrillators: Developing evidence-based care. Nurs Stand. 2003;17:33-36

75. Tagney J, James JE, Albarran JW. Exploring the patient's experiences of learning to live with an implantable cardioverter defibrillator (icd) from one uk centre: A qualitative study. European journal of cardiovascular nursing : journal of the Working Group on Cardiovascular Nursing of the European Society of Cardiology. 2003;2:195-203

76. Dougherty CM. Family-focused interventions for survivors of sudden cardiac arrest. The Journal of cardiovascular nursing. 1997;12:45-58

77. Kaan A, Young QR, Cockell S, Mackay M. Emotional experiences of caregivers of patients with a ventricular assist device. Progress in transplantation. 2010;20:142-147

78. Lichtman JH, Bigger JT, Jr., Blumenthal JA, Frasure-Smith N, Kaufmann PG, Lesperance F, Mark DB, Sheps DS, Taylor CB, Froelicher ES, American Heart Association Prevention Committee of the Council on Cardiovascular N, American Heart Association Council on Clinical C, American Heart Association Council on E, Prevention, American Heart Association Interdisciplinary Council on Quality of C, Outcomes R, American Psychiatric A. Depression and coronary heart disease: Recommendations for screening, referral, and treatment: A science advisory from the american heart association prevention committee of the council on cardiovascular nursing, council on clinical cardiology, council on epidemiology and prevention, and interdisciplinary council on quality of care and outcomes research: Endorsed by the american psychiatric association. Circulation. 2008;118:1768-1775

79. Salmoirago-Blotcher E, Ockene IS. Methodological limitations of psychosocial interventions in patients with an implantable cardioverter-defibrillator (icd) a systematic review. BMC cardiovascular disorders. 2009;9:56

80. Mastenbroek MH, Versteeg H, Jordaens L, Theuns DA, Pedersen SS. Ventricular tachyarrhythmias and mortality in patients with an implantable cardioverter defibrillator: Impact of depression in the midas cohort. Psychosom Med. 2014;76:58-65

81. Frizelle DJ, Lewin RJ, Kaye G, Hargreaves C, Hasney K, Beaumont N, Moniz-Cook E. Cognitivebehavioural rehabilitation programme for patients with an implanted cardioverter defibrillator: A pilot study. British journal of health psychology. 2004;9:381-392 
82. Kohn CS, Petrucci RJ, Baessler C, Soto DM, Movsowitz C. The effect of psychological intervention on patients' long-term adjustment to the icd: A prospective study. Pacing and clinical electrophysiology : PACE. 2000;23:450-456 
Table.1 Participants' Socio-demographic and Clinical Characteristics $(N=263)$

\begin{tabular}{|c|c|}
\hline Characteristics & Mean \pm SD or $n(\%)$ \\
\hline Age, years & $61 \pm 14$ \\
\hline Male & $190(73)$ \\
\hline $\begin{array}{l}\text { Ethnicity } \\
\text { Caucasian, non-Hispanic } \\
\text { African American, non-Hispanic }\end{array}$ & $\begin{array}{l}217(85) \\
37(15)\end{array}$ \\
\hline Married or living with partner & $162(63)$ \\
\hline Education, years & $11 \pm 5$ \\
\hline Anxiety & $68(25)$ \\
\hline Depression & $48(18)$ \\
\hline Previous ICD shock & $95(37)$ \\
\hline $\begin{array}{l}\text { HADS anxiety score, median }\left(25^{\text {th }} \text { percentile, } 75^{\text {th }}\right. \\
\text { percentile) }\end{array}$ & $5(2,8)$ \\
\hline $\begin{array}{l}\text { HADS depression score, median }\left(25^{\text {th }} \text { percentile, }\right. \\
75^{\text {th }} \text { percentile) }\end{array}$ & $3(2,6)$ \\
\hline $\begin{array}{l}\text { Multi-Dimensional Perceived Social Support } \\
\text { Scale score }\end{array}$ & $68 \pm 20$ \\
\hline Control Attitude Scale Revised score & $30.7 \pm 6.5$ \\
\hline $\begin{array}{l}\text { ICD Concerns Questionnaire score, median }\left(25^{\text {th }}\right. \\
\text { percentile, } 75^{\text {th }} \text { percentile) }\end{array}$ & $11(4,24)$ \\
\hline $\begin{array}{l}\text { EQ-5D-3L score, mean SD } \\
\text { median }\left(25^{\text {th }} \text { percentile, } 75^{\text {th }} \text { percentile }\right)\end{array}$ & $.81 \pm .17$ \\
\hline Knowledge of End-Of-Life Issues in ICD score & $7(4,8)$ \\
\hline
\end{tabular}

HADS = Hospital Anxiety and Depression Scale; ICD = I mplantable Cardioverter Defibrillator 
Table 2. Multiple linear regression for prediction of HRQOL ( $N=200)$

\begin{tabular}{|c|c|c|c|c|c|c|c|}
\hline Step & Variable & $\begin{array}{l}\text { Unstandardize } \\
\text { d Coefficient } \beta\end{array}$ & $\begin{array}{l}\text { Standardized } \\
\text { Coefficient } \beta\end{array}$ & $P$ value & $\begin{array}{l}\text { Model Statis } \\
\text { Adjusted } \mathrm{R}^{2}\end{array}$ & $\mathbf{F}$ & p-value \\
\hline \multirow[t]{7}{*}{1} & Age & .00 & -.02 & .75 & .20 & 6.91 & $<.001$ \\
\hline & Gender & -.02 & -.04 & .53 & & & \\
\hline & Received ICD shock & -.00 & -.02 & .80 & & & \\
\hline & Depression & -.09 & -.35 & $<.001$ & & & \\
\hline & Anxiety & -.05 & -.20 & .02 & & & \\
\hline & Social support & .00 & .01 & .89 & & & \\
\hline & ICDC concerns & .00 & .03 & .65 & & & \\
\hline \multirow[t]{7}{*}{2} & Age & .00 & -.02 & .80 & .25 & 7.99 & $<.001$ \\
\hline & Gender & -.02 & -.05 & .43 & & & \\
\hline & Received ICD shock & -.00 & -.01 & .93 & & & \\
\hline & Depression & -.08 & -.29 & $<.001$ & & & \\
\hline & Anxiety & -.04 & -.15 & .049 & & & \\
\hline & Social support & -.001 & -.06 & .37 & & & \\
\hline & ICDC concerns & .001 & .08 & .26 & & & \\
\hline
\end{tabular}




\begin{tabular}{|l|l|l|l|l|l|}
\hline & Perceived control & .01 & .26 & $<.001$ & \\
\hline
\end{tabular}


Table 3. Logistic regression analysis of the relationship between Perceived Control and Quality of Life

\begin{tabular}{|c|c|c|c|c|c|c|c|c|c|c|}
\hline & ${ }^{1}$ Mobility & & ${ }^{2}$ Self-care & & $\begin{array}{l}{ }^{3} \text { Usual } \\
\text { Activities }\end{array}$ & & $\begin{array}{l}{ }^{4} \text { Pain/ } \\
\text { Discomfort }\end{array}$ & & $\begin{array}{l}{ }^{5} \text { Anxiety/ } \\
\text { Depression }\end{array}$ & \\
\hline & $\begin{array}{l}\text { Odds Ratio } \\
(95 \% \mathrm{Cl})\end{array}$ & $P$ & $\begin{array}{l}\text { Odds Ratio } \\
(95 \% \mathrm{Cl})\end{array}$ & $P$ & $\begin{array}{l}\text { Odds Ratio } \\
(95 \% \mathrm{Cl})\end{array}$ & $P$ & $\begin{array}{l}\text { Odds Ratio } \\
(95 \% \mathrm{Cl})\end{array}$ & $P$ & $\begin{array}{l}\text { Odds Ratio } \\
(95 \% \mathrm{Cl})\end{array}$ & $P$ \\
\hline $\begin{array}{l}\text { Male } \\
\text { gender }\end{array}$ & $\begin{array}{c}.83 \\
(.42-1.6)\end{array}$ & .59 & $\begin{array}{c}1.64 \\
(.58-4.61)\end{array}$ & .35 & $\begin{array}{c}.87 \\
(.42-1.80)\end{array}$ & .71 & $\begin{array}{c}.78 \\
(.38-1.61)\end{array}$ & .51 & $\begin{array}{c}1.24 \\
(.57-2.70)\end{array}$ & .59 \\
\hline Age & $\begin{array}{c}1.02 \\
(.99-1.05)\end{array}$ & .56 & $\begin{array}{c}1.00 \\
(.99-1.02)\end{array}$ & .48 & $\begin{array}{c}1.00 \\
(.99-1.01)\end{array}$ & .75 & $\begin{array}{c}1.01 \\
(.98-1.03)\end{array}$ & .67 & $\begin{array}{c}1.00 \\
(.99-1.01)\end{array}$ & .55 \\
\hline $\begin{array}{l}\text { Received } \\
\text { shocks }\end{array}$ & $\begin{array}{c}.97 \\
(.67-1.4)\end{array}$ & .87 & $\begin{array}{c}1.24 \\
(.47-3.30)\end{array}$ & .66 & $\begin{array}{c}3.08 \\
(1.35-7.04)\end{array}$ & .01 & $\begin{array}{c}1.29 \\
(.59-2.84)\end{array}$ & .53 & $\begin{array}{c}1.15 \\
(.53-2.52)\end{array}$ & .73 \\
\hline Anxiety & $\begin{array}{c}1.85 \\
(.49-6.95)\end{array}$ & .36 & $\begin{array}{c}1.16 \\
(.23-5.84)\end{array}$ & .86 & $\begin{array}{c}1.56 \\
(.38-6.41)\end{array}$ & .54 & $\begin{array}{c}11.43 \\
(1.33-98.24)\end{array}$ & .03 & Excluded & \\
\hline Depression & $\begin{array}{c}5.56 \\
(1.41-21.85)\end{array}$ & .01 & $\begin{array}{c}3.15 \\
(.86-11.63)\end{array}$ & .09 & $\begin{array}{c}4.66 \\
(1.11-19.52)\end{array}$ & .04 & $\begin{array}{c}1.89 \\
(.51-7.02)\end{array}$ & .34 & Excluded & \\
\hline $\begin{array}{l}\text { ICD } \\
\text { concerns }\end{array}$ & $\begin{array}{c}1.00 \\
(.98-1.03)\end{array}$ & .94 & Excluded & & $\begin{array}{c}.98 \\
(.95-1.01)\end{array}$ & .12 & $\begin{array}{c}.99 \\
(.97-1.02)\end{array}$ & .82 & $\begin{array}{c}1.03 \\
(1.01-1.06)\end{array}$ & .01 \\
\hline
\end{tabular}




\begin{tabular}{|c|c|c|c|c|c|c|c|c|c|c|}
\hline $\begin{array}{l}\text { Social } \\
\text { support }\end{array}$ & $\begin{array}{c}1.01 \\
(.99-1.02)\end{array}$ & .67 & $\begin{array}{c}1.03 \\
(1.001-1.06)\end{array}$ & 0.45 & $\begin{array}{c}1.01 \\
(.99-1.03)\end{array}$ & .22 & $\begin{array}{c}.99 \\
(.98-1.01)\end{array}$ & .82 & $\begin{array}{c}.99 \\
(.97-1.003)\end{array}$ & .97 \\
\hline $\begin{array}{l}\text { Low } \\
\text { perceived } \\
\text { control }\end{array}$ & $\begin{array}{c}2.05 \\
(1.05-3.99)\end{array}$ & .04 & $\begin{array}{c}3.97 \\
(1.42-11.07)\end{array}$ & .01 & $\begin{array}{c}3.79 \\
(1.88-7.62)\end{array}$ & $<.001$ & $\begin{array}{c}2.93 \\
(1.49-5.72)\end{array}$ & $<.01$ & $\begin{array}{c}3.09 \\
(1.45-6.58)\end{array}$ & $<.01$ \\
\hline
\end{tabular}

$\mathrm{Cl}=$ Confidence Interval; $\mathrm{ICD}=$ Implantable Cardioverter Defibrillator

\section{Summary of model statistics}

${ }^{1} X^{2}(d f=11, n=200)=27.024, p<.01$. Cox and Snell $R^{2}=0.12$, Nagelkerke $R^{2}=0.17$. The model correctly classified $65 \%$ of cases. Hosmer and Lemeshow test $\left(X^{2}(d f=8, n=200)=4.889, p=0.769\right)$.

${ }^{2} X^{2}(\mathrm{df}=10, \mathrm{n}=234)=22.040, p=.02$. Cox and Snell $R^{2}=0.09$, Nagelkerke $R^{2}=0.16$. The model correctly classified $88 \%$ of cases. Hosmer and Lemeshow test $\left(X^{2}(d f=8, n=234)=13.855, p=0.086\right)$.

${ }^{3} X^{2}(d f=10, n=234)=49.123, p<.001$. Cox and Snell $R^{2}=0.19$, Nagelkerke $R^{2}=0.25$. The model correctly classified $71 \%$ of cases. Hosmer and Lemeshow test results confirmed that the model was a good fit for the data, $X^{2}(\mathrm{df}=8, n=234)=7.478, p=$ 0.252 .

${ }^{4} X^{2}(d f=11, n=200)=38.936, p<.001$. Cox and Snell $R^{2}=0.18$, Nagelkerke $R^{2}=0.24$. The model correctly classified $67 \%$ of cases. Hosmer and Lemeshow test $\left(X^{2}(d f=8, n=200)=3.183, p=0.922\right)$.

${ }^{5} X^{2}(d f=7, n=207)=39.714, p<.001$. Cox and Snell $R^{2}=0.18$, Nagelkerke $R^{2}=0.25$. The model correctly classified $71 \%$ of cases.

Hosmer and Lemeshow test $\left(X^{2}(d f=8, n=207)=50144, p=0.742\right)$. 
Table 4. Multiple linear regression for prediction of perceived control $(N=201)$

\begin{tabular}{|c|c|c|c|c|c|c|}
\hline Step & Variable & $\begin{array}{l}\text { Unstandardized } \\
\text { Coefficient } \beta\end{array}$ & $\begin{array}{l}\text { Standardized } \\
\text { Coefficient } \beta\end{array}$ & $P$ value & $\begin{array}{l}\text { Model statistics } \\
\text { Adjusted } \mathrm{R}^{2}\end{array}$ & p- value \\
\hline \multirow[t]{3}{*}{1} & Age & .06 & .12 & .08 & 2.89 & .04 \\
\hline & Gender & 1.07 & .07 & .31 & & \\
\hline & $\begin{array}{l}\text { Received shock from } \\
\text { ICD }\end{array}$ & -1.18 & -.15 & .03 & & \\
\hline \multirow[t]{8}{*}{2} & Age & -.01 & -.01 & .87 & 10.44 & $<.001$ \\
\hline & Gender & .55 & .04 & .56 & & \\
\hline & Received ICD shock & -.28 & -.04 & .58 & & \\
\hline & Depression & -2.40 & -.23 & $<.01$ & & \\
\hline & Anxiety & -1.75 & -.17 & .02 & & \\
\hline & Social support & .08 & .26 & $<.01$ & & \\
\hline & ICDC concerns & -.07 & -.16 & .02 & & \\
\hline & ICD knowledge & -.004 & -.03 & .98 & & \\
\hline
\end{tabular}

